\title{
Álvaro Vallejo Campos, Adonde nos lleve el logos. Para leer la República de Platón, Madrid, Trotta, 2018, 368 pp.
}

工l a contribución de Álvaro Vanos lleve el logos. Para leer la República de Platón, constituye tanto una guía como un estado de la cuestión, comentario y análisis de las cuestiones más sobresalientes de cada uno de los diez libros de un diálogo que de por sí se destaca dentro de la obra platónica. En efecto, tal y como lo señala el autor, la República es una de las composiciones más importantes del filósofo ateniense no solo por su extensión, su contenido y su belleza literaria, sino también por su enorme influencia en la historia del pensamiento filosófico tanto occidental como oriental. Este solo hecho podría servir de justificativo para la redacción del trabajo que aquí se reseña, trabajo que ciertamente forma parte de una inmensa bibliografia académica, entre cuyas últimas producciones de análisis abarcativo sobre la República se encuentran las de Vegetti, Dixsaut-Teisserenc, Rosen, Santas y Ferrari. Podría objetarse que con la existencia de estos aportes el de Vallejo Campos resultaría prescindible. Sin embargo, consideramos que hay ciertas razones de peso que van en contra de esta objeción. En primer lugar, cabe remarcar el carácter multifacético al que antes hicimos mención. Este no es un rasgo menor, ya que de las producciones antes nombradas solo la de Vegetti corre con esta ventaja, que se ve contrarrestada por su extensión -en siete tomos-. De todas estas contribuciones, la obra de Campos se destaca por su posición anfibia entre la erudición y la divulgación, posición que la vuelve asible tanto para quienes se inician en el estudio del pensamiento del filósofo ateniense como para los especialistas. Podría objetarse, por otro lado, que el aporte de Rosen tiene también esta característica; sin embargo, es necesario reconocer que la omisión en su análisis de gran parte de la literatura secundaria sobre la República limita, en alguna medida, el valor que su obra pueda tener para los investigadores. Volviendo a la contribución de Vallejo Campos, cabe destacar además que es la única en su tipo -en tanto estado de la cuestión, comentario y análisis de la República en su totalidad- pensada y escrita en español. Por último, es necesario tener en cuenta además que, si bien muchos de los aportes de los trabajos antes referenciados siguen aún vigentes, todos ellos fueron elaborados hace más de diez años atrás, lo que reclama, en algún sentido, la existencia de una obra que rescate las últimas discusiones sobre las diversas temáticas del diálogo. Estas razones, además de las que el lector pueda encontrar por su cuenta, hacen del trabajo de Vallejo Campos una adición valiosa al catálogo de investigaciones sobre la filosofía platónica. 
En el prólogo a la obra, el autor indica a sus lectores que su comentario y análisis sobre la República parte en este caso de la perspectiva de lo utópico, en función de la cual se caracteriza al discurso filosófico presente en el diálogo como aquel que intenta ofrecer una alternativa al status quo y, en este sentido, como valioso en tanto cuestionamiento a la ideología de época de la Atenas clásica. Este posicionamiento recupera, según lo indica el mismo autor, las reflexiones de Mannheim, para quien "un estado mental es utópico cuando es incongruente con el estado de realidad dentro del cual ocurre" y "esta incongruencia es siempre evidente en el hecho de que tal estado mental en la experiencia, en el pensamiento y en la práctica está orientado a objetos que no existen en la situación actual". Ahora bien, Mannheim es especialmenpensamiento utópico y cualquier otro que también trascienda la situación inmediata y sea incongruente con ella, en el hecho de que las orientaciones del primero, al pasar a la acción, tienden a hacer añicos, parcial o completamente, el orden de cosas prevaleciente en determinado momento. Esta diferencia es clave, no solo en la exposición de Mannheim -que no refiere a la obra platónica en ningún momento- sino en la perspectiva de análisis de Vallejo Campos, ya que, como antes se mencionó, la lectura que este autor hace sobre la República parte de la concepción de este diálogo como una crítica a la realidad de su tiempo que tiene como objetivo su transformación.

En línea con esto, el autor del trabajo que aquí se reseña señala que el utopismo presente en la República no es superficial ni accidental, sino que se encuentra vinculado internamente con los posicionamientos ontológicos y epistemológicos que hacen al corazón de la filosofía de Platón. Su crítica a la opinión de la mayoría y a aquello que la forma y/o representa -siendo en esta ocasión Homero su exponente más visible- no puede fundarse sino en la convicción de que existe algo que la supera - en este caso el saber o epistéme- por la perfección de su objeto -las Formas o Ideas-.

Al prólogo le sucede una introducción general en la que se establece el tema fundamental del diálogo -qué es la justicia-, los cruces interdisciplinarios a propósito de él -antropología, psicología, política, epistemología y ontologíay algunas consideraciones estilísticas que conducen a la presentación de la discusión en torno a la unidad y sistematicidad del pensamiento platónico -debate unitarismo/evolucionismo, interpretaciones esoteristas-. Además, se dedica un espacio a las posturas más influyentes del siglo XX sobre la manera en que debe interpretarse la propuesta política esbozada en el diálogo. Entre ellas se destaca la de Popper en su trabajo La sociedad abierta y sus enemigos, según la cual la propuesta platónica constituiría un antecedente del totalitarismo moderno. A esta se contrapone la de Gadamer, para quien la República no puede leerse de manera literal sino dentro del género de lo utópico entendido este como un "modo de pensar" sin pretensiones de realizar aquello que piensa. Por último, se presentan las propuestas de lectura de Strauss, Guthrie y Griswold, que entienden el proyecto político del diálogo como irrealizable e incluso indeseable. Vallejo Campos, por su parte y siguiendo a Vegetti, revaloriza el carácter político de la República respetando el texto 
y sin pretender dar excusas por aquello que resulte chocante para el lector moderno. A continuación, el autor sienta también posición en lo que respecta a la unidad de la obra: si bien existen ciertas inconsistencias internas que se explican por su largo período de composición, la República encuentra su unidad en la discusión en torno a la teoría de la justicia defendida por Sócrates a propósito de las posturas contrarias de Trasímaco -quien sostiene la idea de justicia del más fuerte-, por un lado, y de Glaucón y Adimanto por el otro -quienes proponen una teoría contractual-. En este marco, el rol que se le adjudica al alma según Vallejo Campos es central, puesto que la justicia es concebida como una virtud que se manifiesta primeramente no en el comportamiento con los otros, sino en la armonía que surge del concierto entre las partes del alma de cada individuo.

A esta introducción general le siguen diez capítulos correspondientes a cada uno de los diez libros de la $R e$ pública. Si bien algunos de ellos cuentan con introducciones propias y otros no, lo común a todos es la división por tema respetando el orden original del diálogo. Retomando lo que ya se dijo, el comentario y análisis realizado por Campos trata las cuestiones más sobresalientes y discutidas por la investigación erudita, tales como la tripartición del alma (434d-441c), el gobierno de los filósofos (471d-474a), la caracterización de las Formas o Ideas (474b-480a), la analogía del Bien con el sol (506d-509c), la línea dividida (509d6-511e5), la alegoría de la caverna (514a-521b), los distintos tipos de gobierno de la pólis $(547 c-569 c)$, las críticas a la poesía (598d-605c) y los mitos de los metales (412b-417a) y de Er (614a-621d). Asimismo, aquellos otros aspectos -como la igualdad de las mujeres (451c-457c) o lo que Vallejo Campos llama "pautas de la teología" (377b-383c) - tratados por la investigación filosófica de manera menos frecuente también son expuestos y comentados de forma clara, simple sin sacrificar profundidad-y completa.

Como se puede apreciar por lo expuesto hasta aquí, la tarea emprendida por el autor es de una complejidad y una envergadura de dimensiones colosales, que fácilmente podría haber devenido en un collage caótico de comentarios tendientes a confundir y repeler tanto a los lectores recién iniciados como a los especialistas. Afortunadamente, este no es el caso, puesto que la capacidad explicativa, el conocimiento erudito y la predilección por el pensamiento platónico se conjugan en la contribución de Vallejo Campos para encantarnos a lo largo de un entusiasmado camino de análisis sobre una de las obras más bellas, profundas y provocadoras de la historia de la filosofía.

ANA J. FERNÁNDEZ PALAZZO $U N L P$ 